\title{
Gender-Based Power and Couples' HIV Risk In Uttar Pradesh and Uttarakhand, North India
}

\section{By Alpna Agrawal, Shelah S. Bloom, Chirayath Suchindran, Siân Curtis and Gustavo Angeles}

Alpna Agrawal is a medical student, School of Medicine, University of Texas Health Science Center at Houston, USA. Shelah S. Bloom is research assistant professor, and Siân

Curtis is research associate professor, Department of Maternal and Child Health; Chirayath Suchindran is professor, Department of Biostatistics; and Gustavo Angeles is research assistant professor, Department of Maternal and Child Developmentall at the University of North Carolina at Chapel Hill, USA.

\begin{abstract}
CONTEXT: Gender inequality is a long-recognized driver of the HIV epidemic. However, few studies have investigated the association between gender-based power and HIV risk in India, which has the world's third largest HIV epidemic.
\end{abstract}

METHODS: Population-based data collected in 2003 from 3,385 couples residing in Uttar Pradesh and Uttarakhand, North India, were used to examine associations between gender-based power (wife's autonomy and husband's inequitable gender attitudes) and indicators of couples' HIV risk (whether the husband had had premarital sex with someone other than his eventual spouse, extramarital sex in the past year or STI symptoms in the past year). Structural equation modeling was used to create composite variables for the gender-based power measures and test their associations with HIV risk measures.

RESULTS: Twenty-four percent of husbands had had premarital sex, 7\% had had extramarital sex in the past year and $6 \%$ had had STI symptoms in the past year. Structural equation models indicated that wives who reported higher levels of autonomy were less likely than other wives to have husbands who had had extramarital sex in the past year (direct association) or STI symptoms in the past year (indirect association). Moreover, husbands who endorsed more inequitable gender attitudes were more likely than others to report having had premarital sex with someone other than their spouse, which in turn was associated with having had extramarital sex and STI symptoms in the past year.

CONCLUSIONS: If the associations identified in this study reflect a causal relationship between gender-based power and HIV risk behavior, then HIV prevention programs that successfully address inequitable gender roles may reduce HIV risks in North India.

International Perspectives on Sexual and Reproductive Health, 2014,40(4):196-205, doi: 10.1363/4019614

In the context of the HIV epidemic, gender-based power refers to power differentials-such as women's subordination and men's control over decision making, including in sexual relationships-that directly or indirectly influence women's and men's susceptibility to HIV. ${ }^{1}$ The World Health Organization, the Joint United Nations Programme on HIV/AIDS and the (U.S.) President's Emergency Plan for AIDS Relief state that gender-based power plays a critical role worldwide in driving the spread of $\mathrm{HIV}^{2-4}$

Although HIV programs have sought, since the late 1980s, to address gender dynamics that contribute to risky sexual behavior, recent research and policy initiatives have called for HIV programs to explicitly reduce gender inequality. ${ }^{1,3}$ International agencies recommend making gender issues a standard component of HIV prevention programs and analyzing study results by gender to "generate better evidence and increased understanding of the specific needs of women and girls in the context of HIV."

Globally, India ranks third, after South Africa and Nigeria, in the number of people living with HIV. ${ }^{5}$ Men's risky sexual behaviors-including premarital sex, extramarital sex and transactional sex, all of which are frequently unprotected-play a substantial role in the spread of HIV and other STIs in the subcontinent, ${ }^{6-9}$ and result in the transmission of the virus to women who otherwise would have little or no risk of infection. ${ }^{9,10}$ Although gender inequity has been linked to HIV risk in India, ${ }^{11}$ empirical evidence of the relationship between gender-based power and HIV risk is limited, particularly for North India, where most HIV research has focused on high-risk populations rather than on gender dynamics. ${ }^{7,12}$ However, research in the United States, Sub-Saharan Africa and South America has shown that gender inequity is associated with high-risk sex, infrequent condom use, STI symptoms and sexual violence. ${ }^{13,14}$

The current study investigated the relationship between gender-based power and HIV risk among couples in Uttar Pradesh and Uttarakhand (the former hill region of Uttar Pradesh), North India. Fewer HIV studies have focused on North India than on South India. ${ }^{15}$ Uttar Pradesh has 199 million inhabitants and is India's most populous state, ${ }^{16}$ only five countries in the world have larger populations. ${ }^{17}$ Although the prevalence of HIV in Uttar Pradesh is low $(0.07 \%)$, the state is considered "highly vulnerable" to HIV spread because of its poor performance on indicators of health, development and gender equity (e.g., women's education, age at marriage, gender-based violence). ${ }^{18}$ In 
addition, Uttar Pradesh's levels of sex trafficking and interstate migration-both of which are associated with HIV spread in India-are among the highest in the country. ${ }^{19}$ According to estimates by the National AIDS Control Organisation, rates of HIV transmission have increased in Uttar Pradesh, and North India accounted for $41 \%$ of new HIV infections nationally in 2008-2009. ${ }^{20}$

\section{Conceptual Model}

The current study was informed by Wingood and DiClemente's application of Connell's theory of gender and power to HIV risks. ${ }^{1}$ According to this theory, relationships between men and women are characterized by three social structures: sexual division of labor, which pertains to economic inequality; sexual division of power, which refers to an individual's ability to act, change or have power over others; and cathexis, which concerns the norms, attitudes and beliefs related to society's expectations of men and women. HIV studies that have applied this theory have shown that women who experience imbalances in gender-based power are at elevated risk for HIV., 1 21-24

The theory of gender and power was a logical choice to guide this study in light of the inequitable gender practices in India and their potential role in the spread of HIV. Nationally, $37 \%$ of ever-married Indian women report having been physically or sexually abused by their husband, and $54 \%$ believe it is justifiable for husbands to beat their wife. ${ }^{18}$ In India, most women who become infected with HIV do so through heterosexual sex with their husband. ${ }^{9,10,25}$ In the current study, we examined wife's autonomy and husband's inequitable gender attitudes-which are related to sexual division of power and cathexis, respectively, in the theory of gender and power-because they may be directly related to relationship power and, in turn, HIV risk. Generally, women's autonomy is associated with improved reproductive and sexual health, while men's inequitable attitudes toward women are associated with sexual health risks. $^{26-29}$

\section{METHODS}

\section{Study Population}

This study was part of a larger project, funded by the U.S. National Institute for Child Health and Human Development, that explored the potential for the spread of HIV in North India. The data were collected from January to July 2003 from a probability sample of 3,385 married couples residing in Uttar Pradesh and Uttarakhand, and the sample is representative of couples living in major urban cities and rural areas in these states.

A multistage cluster sampling design was used to obtain the sample. Women were eligible to be interviewed if they were married, living with their spouse and aged 15-49. Husbands of participating wives were also interviewed. In total, interviewers visited 3,324 households and completed interviews with 3,501 of the 3,588 eligible wives; 76 wives could not be reached and 11 refused to be interviewed. In addition, interviews were completed with 3,412 of the 3,588 eligible husbands; 130 husbands could not be contacted and 46 refused to be interviewed. Husbands and wives whose spouse was not interviewed were excluded from our analysis; 27 other couples were excluded because of missing or inconsistent data on key variables. The final analytic sample consisted of 3,385 couples.

Informed consent was obtained from both spouses and the head of the household (if other than the husband or wife). All questionnaires were translated into colloquial Hindi and administered in this language. Data entry was carried out using EPINFO software.

A household interview was conducted with the head of the sampled household or another informed adult member and collected information on the household's standard of living. The individual interviews for wives and husbands included questions on social and demographic characteristics, substance use, work mobility, self-reported STI symptoms and gender norms. The husbands' survey also solicited information on premarital and extramarital sexual behavior, using a standard partner history for the man's last three partners in the past 12 months. This information was collected only from husbands because preliminary work for this study indicated that cultural norms and personal safety issues precluded asking wives about extramarital sexual behavior. ${ }^{30}$ Data on husbands' responses were linked to data on wives' responses.

Study approval was obtained from the internal review board of the Indian Council of Medical Research in India and from the Public Health-Nursing Internal Review Board at the University of North Carolina at Chapel Hill.

\section{Measures}

- Couple's HIV risk. Husbands were asked whether they had engaged in premarital sex with someone other than their current wife, had had extramarital sex in the past year or had had any STI symptoms (specifically penile discharge or penile ulcers) in the past year. We included premarital sex because in India it has been linked to extramarital sex as well as to HIV infection. ${ }^{6}$

- Gender-based power. Gender-based power was captured using measures of wife's autonomy and husband's inequitable gender attitudes. Autonomy was measured using a total of 15 items that, in accordance with previous research, ${ }^{31}$ asked wives about their level of interpersonal control in multiple dimensions: finances, household decision making, mobility and leniency. In the finances dimension, wives were asked whether they could spend money on four types of items: a small present; kitchen pots; jewelry; and an almari (cabinet), bed or fan. In the realm of household decision making, four items assessed whether wives participated in decisions about buying food, clothes, kitchen items and major household items. For the mobility dimension, three items asked whether wives could go alone to a health facility, the nearby home of a friend or relative, or a nearby bazaar. Finally, for the leniency dimension, wives were asked if they needed permission to go to a market, a nearby friend's or relative's home, a wedding 
TABLE 1. Percentage of wives and husbands with selected characteristics, Uttar Pradesh and Uttarakhand, India, 2003

\begin{tabular}{llr} 
Measure & $\begin{array}{l}\text { Wives } \\
(\mathrm{N}=3,385)\end{array}$ & $\begin{array}{l}\text { Husbands } \\
(\mathrm{N}=3,385)\end{array}$ \\
\hline COVARIATES & & \\
Age & & \\
$15-24$ & 21.8 & 8.2 \\
$25-29$ & 27.9 & 21.6 \\
$30-39$ & 36.4 & 39.2 \\
$\geq 40$ & 13.9 & 31.1 \\
& & \\
Education & & \\
None & & \\
$1-8$ yrs. & 45.9 & 22.0 \\
$9-12$ yrs. & 24.6 & 25.9 \\
$\geq 13$ yrs. & 17.6 & 32.2 \\
& 11.9 & 20.0
\end{tabular}

\section{Standard of living}

Low

Medium

High

Residence

Urban

Rural

Regiont

Bundelkhand 20.1

Central $\quad 19.8$

Eastern

Western

Uttarakhand

Used alcohol/marijuana in past two weeks na

Mobility

GENDER-BASED POWER

Wife's autonomy

Can always spend money on small presents 9.8

Can always participate in buying clothes 37.9

Can go alone to nearby bazaar $\quad 33.9$

Never needs permission to go to

health facility when sick

4.7

Husband's inequitable gender attitudes

There is no harm if a wife sometimes disobeys

her husband's instructions

Agrees

Disagrees§

na

A wife should always consult her husband on any decision, large or small

Agrees§

Disagrees

na

82.7

There is no harm if a wife goes out alone

to nearby home of friend/relative

Agrees

Disagrees§

\section{na}

na

51.9

HIV RISK INDICATORS

Husband had premarital sext+ na $\quad 24.2$

Husband had extramarital sex in past year na -7.1

Husband had STI symptoms in past year

†All but Uttarakhand are subdivisions of Uttar Pradesh. $¥$ One item from each dimension of women's autonomy is shown; a total of 15 items were assessed. \$Response represents inequitable gender attitude. t+With someone other than his eventual spouse. Notes: Percentages may not total

100.0 because of rounding . $a=$ not applicable. or a health facility. Women responded to these items using a three- or four-point Likert scale; responses were recoded so that higher scores indicated higher levels of autonomy.

Our measure of inequitable gender attitudes assessed husbands' attitudes toward wives acting independently. The three items were drawn from qualitative research with husbands in the study sample. ${ }^{32}$ Husbands were asked to rate their level of agreement with the following statements: There is no harm if a wife sometimes disobeys her husband; a wife should always consult her husband before making decisions, large or small; and there is no harm if a wife goes out alone to the nearby house of a friend or relative. Men responded to these statements using a fourpoint scale that ranged from "strongly agree" to "strongly disagree"; responses were recoded as either "agree" or "disagree." In addition, responses to the first and third items were recoded so that a higher score indicated that husbands endorsed more inequitable gender attitudes.

- Covariates. Covariates included in our analyses were age, educational level, household standard of living, area of residence, region, husband's recent substance use and mobility of husband's work. Age was categorized as 15-24, 25-29, 30-39 or 40 or older; education as none, 1-8 years, 9-12 years or 13 or more years. We classified household standard of living as low, medium or high according to an index, developed for previous population-based surveys in India, ${ }^{18}$ that is based on ownership of certain items, vehicles, animals, land and other assets. Area of residence was characterized as urban or rural. Region of residence was categorized as western, central, Bundelkhand, eastern or Uttarakhand, and was included because HIV risk and prevalence vary by geography in Uttar Pradesh. ${ }^{19}$

Our measure of recent substance use indicated whether a husband reported having used alcohol or marijuana (eaten in the form of bhang) during the past two weeks. Husband's mobility was a binary variable that indicated whether the husband had slept away from home because of work at least one night in the past four weeks or for more than two consecutive weeks in the past year. Substance use and mobility were included in our analyses because they are associated with HIV risk in India. ${ }^{7,19}$

\section{Analytic Plan}

We used structural equation modeling to identify direct and indirect associations between gender-based power measures and HIV risk indicators (whether the husband had had premarital sex, had had extramarital sex in the past year or had had STI symptoms in the past year). Although structural equation models are typically used to test hypothesized direct causal relationships between variables (as well as indirect associations, mediated through one or more other variables, that take into account covariance patterns among variables), they do not establish causality, but rather only indicate associations among variables. ${ }^{33,34}$ In this study, an advantage to using structural equation modeling was that it allowed us to model the gender-based power measures as separate factors while evaluating their 


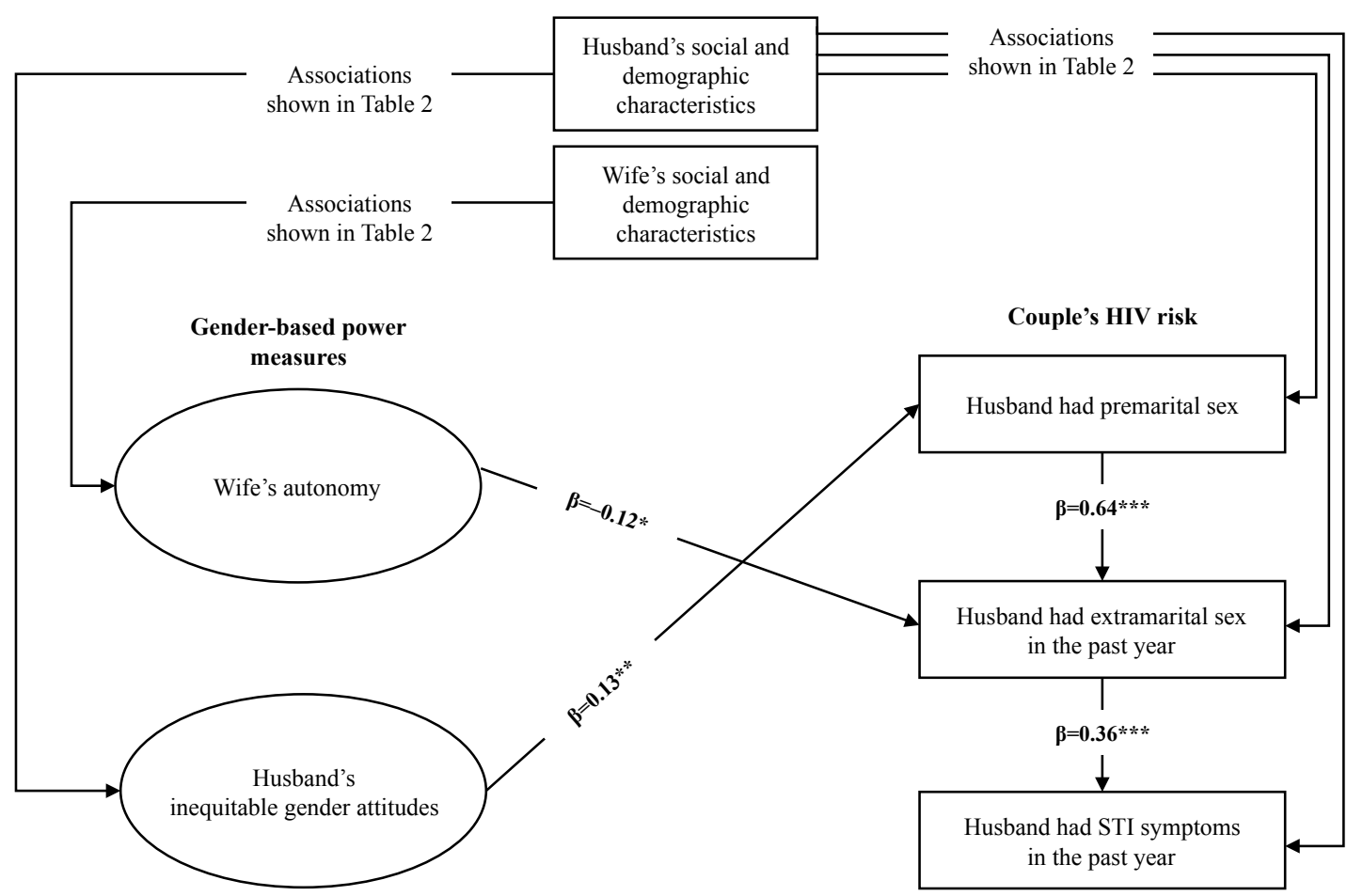

${ }^{*} \mathrm{p}<.05 .{ }^{* *} \mathrm{p}<.01 .{ }^{* * *} \mathrm{p}<.001$. Notes: Model controls for age, education, husband's use of alcohol/marijuana in past two weeks, husband's mobility, standard of living, area of residence and region. Arrows show direct, statistically significant associations; figure does not show indirect and total effect of wife's autonomy on husband's STI symptoms in past year ( $\beta=-0.04^{*}$ and $-0.15^{*}$, respectively), or indirect effect of husband's inequitable gender attitudes on extramarital sex in past year $\left(\beta=0.08^{* *}\right)$ and STI symptoms in past year $\left(\beta=0.03^{* *}\right)$. Model fit was good (comparative fit index $=0.92 ;$ TuckerLewis index $=0.92$; root mean square error of approximation $=0.04$ ).

associations with HIV risk in a single model, an approach we considered appropriate given that the three structures of the theory of gender and power have been described as being distinct, yet related, and as collectively influencing HIV risks. ${ }^{1}$ On the basis of previous research, we hypothesized that a wife's autonomy would be negatively associated with HIV risk, and that a husband's inequitable gender attitudes would be positively associated with HIV risk.

Modeling followed a two-step process. First, we performed confirmatory factor analyses to construct composite factors for the gender-based power measures. To estimate the factor for wife's autonomy, we performed firstand second-order confirmatory factor analyses assessing the measure's reliability and validity. The first-order factor model allowed us to test covariance among items for each dimension of wife's autonomy; the second-order factor model allowed us to test covariance among the four dimensions of wife's autonomy. The three survey items measuring husband's inequitable gender attitudes were modeled on a single factor.

Next, we specified a structural equation model to test the hypothesized relationships between gender-based power and HIV risk indicators while adjusting for covariates. Because the gender-based power measures were categorical, we estimated the parameters by weighted least-squares using robust standard errors and mean- and variance-adjusted chi-square test statistics (previous work has shown that this approach can be used with categorical variables ${ }^{35}$ ). Standard errors were adjusted for clustering Because the quantity of missing data was small, we used listwise deletion. We report standardized beta estimates for all direct, indirect and total effects.*

To evaluate model fit in the confirmatory and structural equation models, we used three indices: the comparative fit index (CFI), the Tucker-Lewis index (TLI) and the root mean square error of approximation (RMSEA). Models are generally considered to have adequate fit if scores on the first two indices are greater than 0.9 and that on the last is 0.06 or less. ${ }^{35}$ Descriptive analyses were performed in Stata 10.0 , and structural equation modeling was conducted in Mplus version 5.0.

\section{RESULTS}

\section{Sample Characteristics}

Twenty-two percent of wives were younger than 24, compared with $8 \%$ of husbands (Table 1), and wives were twice as likely as husbands to have no formal education (46\% vs. 22\%). Almost one-third (30\%) of husbands had used alcohol or marijuana in the past two weeks, and one

*We use the word "effect" in accordance with standard structural equation modeling terminology. However, as we noted earlier, the technique cannot prove a causal relationship. 
in seven (14\%) were categorized as mobile.

Wife's level of autonomy varied across dimensions. Table 1 presents a representative selection of the autonomy measures. For example, 10\% of wives said that they could always spend money on small presents (finances dimension), 38\% could always participate in buying clothes (decision making), 34\% could visit a nearby bazaar alone (mobility) and 5\% never needed permission to visit a health facility when sick (leniency).

Inequitable gender attitudes were pervasive among husbands. The majority of husbands felt that wives should consult their spouse on any decision, large or small (83\%); three-fifths said that a wife should not disobey her husband's instructions (58\%); and almost half indicated that a wife should not go out alone to visit a nearby friend or relative (48\%).

One in four husbands (24\%) had had premarital sex with someone other than their current wife. Smaller proportions of husbands reported having had extramarital sex $(7 \%)$ or STI symptoms (6\%) in the past year.

\section{Confirmatory Factor Analysis}

In the first-order confirmatory factor model for wife's autonomy, the standardized factor loadings of each dimension's respective indictors ranged from 0.7 to 0.9 ( $p<.001)$ and demonstrated adequate model fit (RMSEA $=0.06$, $\mathrm{CFI}=0.96$, TLI=0.97). For the second-order factor of the wife's autonomy items, the standardized factor loadings of each dimension ranged from 0.4 to 0.9 ( $\mathrm{p}<.001$ ), and the overall model fit was adequate (RMSEA $=0.06, \mathrm{CFI}=0.94$, TLI=0.96). For the husband's inequitable gender attitudes factor, the standardized factor loadings for the three indictors ranged from 0.3 to 0.9 ( $\mathrm{p}<.001)$. The wife's autonomy factor was not significantly correlated with the husband's inequitable gender attitudes factor $(\mathrm{p}=0.41)$.

\section{Multivariate Structural Equation Model}

The fit indices of the structural equation model indicated good fit (Figure 1, page 199).

-Associations of covariates with gender-based power. Wives aged 25-29, 30-39, or 40 or older reported higher levels of autonomy than did wives aged 15-24 (Table 2). In addition, wives with at least nine years of education reported higher levels of autonomy than did wives with no education. Among husbands, recent substance use was negatively associated with inequitable gender attitudes.

- Associations of covariates with indicators of HIV risk. Husbands with higher levels of education tended to be less likely to report premarital sex, extramarital sex and STI symptoms than were husbands with no education. Hus-

\begin{tabular}{|c|c|c|c|c|c|}
\hline \multirow[t]{2}{*}{ Characteristic } & \multicolumn{2}{|c|}{ Gender-based power } & \multicolumn{3}{|l|}{ Couple's HIV risks } \\
\hline & Wife's autonomy & $\begin{array}{l}\text { Husband's } \\
\text { inequitable } \\
\text { gender attitudes }\end{array}$ & $\begin{array}{l}\text { Husband had } \\
\text { premarital sex } †\end{array}$ & $\begin{array}{l}\text { Husband had } \\
\text { extramarital } \\
\text { sex in past year }\end{array}$ & $\begin{array}{l}\text { Husband had } \\
\text { STI symptoms } \\
\text { in past year }\end{array}$ \\
\hline \multicolumn{6}{|l|}{ Wife's age } \\
\hline $15-24$ (ref) & 0.00 & na & na & na & na \\
\hline $25-29$ & $0.20^{* * *}$ & na & na & na & na \\
\hline $30-39$ & $0.32^{* * *}$ & na & na & na & na \\
\hline$\geq 40$ & $0.35^{* * *}$ & na & na & na & na \\
\hline \multicolumn{6}{|l|}{ Husband's age } \\
\hline $15-24$ (ref) & na & 0.00 & 0.00 & 0.00 & 0.00 \\
\hline $25-29$ & na & 0.00 & -0.02 & -0.00 & -0.04 \\
\hline $30-39$ & na & -0.06 & 0.05 & 0.05 & $-0.14^{*}$ \\
\hline$\geq 40$ & na & -0.06 & $0.09^{* *}$ & -0.10 & -0.10 \\
\hline \multicolumn{6}{|l|}{ Wife's education } \\
\hline None (ref) & 0.00 & na & na & na & na \\
\hline $1-8$ yrs. & 0.03 & na & na & na & na \\
\hline $9-12$ yrs. & $0.09^{* * *}$ & na & na & na & na \\
\hline$\geq 13$ yrs. & $0.15^{* * *}$ & na & na & na & na \\
\hline \multicolumn{6}{|l|}{ Husband's education } \\
\hline None (ref) & na & 0.00 & 0.00 & 0.00 & 0.00 \\
\hline $1-8$ yrs. & na & 0.02 & -0.03 & -0.05 & -0.03 \\
\hline $9-12$ yrs. & na & -0.02 & -0.05 & $-0.08^{*}$ & -0.07 \\
\hline$\geq 13$ yrs. & na & -0.07 & $-0.12^{* * *}$ & -0.08 & $-0.15^{*}$ \\
\hline \multicolumn{6}{|l|}{ Standard of living } \\
\hline Low (ref) & 0.00 & 0.00 & 0.00 & 0.00 & 0.00 \\
\hline Medium & -0.03 & -0.01 & $-0.13^{* * *}$ & 0.09 & -0.01 \\
\hline High & -0.02 & -0.01 & $-0.18^{* * *}$ & 0.09 & 0.04 \\
\hline \multicolumn{5}{|l|}{ Husband used alcohol/marijuana in } & 0.08 \\
\hline Husband's mobility & na & -0.01 & $0.06^{* * *}$ & $0.05^{*}$ & 0.04 \\
\hline
\end{tabular}


bands in households with a medium or high standard of living were less likely to report premarital sex than were those with a low standard of living.

Husbands who reported recent substance use had an elevated likelihood of reporting premarital sex and extramarital sex in the past year. Husbands who had made overnight trips for work were more likely than those who had not been away from home to report having had premarital sex with a woman other than their eventual wife and having had extramarital sex in the past year.

- Associations between HIV risk indicators. HIV risk indicators reported by husbands were positively associated with each other after adjustment for covariates (Figure 1). A husband's having had premarital sex was directly and positively associated with having had extramarital sex in the past year (coefficient, 0.64), and indirectly and positively associated with having had STI symptoms in the past year (0.24, p<.001; not shown). In addition, a husband's having had extramarital sex in the past year was directly and positively associated with having had STI symptoms in the past year (0.36; Figure 1).

-Associations of gender-based power with HIV risk indicators. Wife's autonomy was directly and negatively associated with husband's having had extramarital sex in the past year (coefficient, -0.12). A negative association was apparent between wife's autonomy and husband's having had STI symptoms in the past year $(-0.04$ indirect effect and -0.15 total effect; not shown). A direct association between wife's autonomy and a husband's STI symptoms was marginally significant $(-0.11, \mathrm{p}=.06)$.

Husband's inequitable gender attitudes were directly and positively associated with his having had premarital sex (coefficient, 0.13; Figure 1). In addition, husband's inequitable gender attitudes were indirectly and positively associated with his having had extramarital sex in the past year and having had STI symptoms in the past year (0.08 and 0.03 , respectively; not shown).

\section{DISCUSSION}

Our analysis of data from a population-based sample of 3,385 couples in North India showed that gender-based differences in power were associated with indicators of HIV risk. The findings concerning a wife's autonomy complement previous research in India showing that autonomy is associated with measures of reproductive health, such as antenatal care utilization, family planning access, contraceptive use and child health. ${ }^{27,36}$ However, few studies have considered the role of autonomy with respect to HIV risk. Studies to date suggest that autonomy may facilitate HIV prevention and risk reduction. In Uttar Pradesh, a wife's autonomy was positively correlated with her awareness of HIV and condom use. ${ }^{28}$ A multistate analysis in India showed a negative association between a woman's autonomy and initiation of marital violence by her husband, an emerging HIV risk factor. ${ }^{37,38}$ We extend the current literature by demonstrating direct and indirect negative associations between a wife's autonomy and indicators of HIV risk. A potential explanation for these findings is that higher levels of autonomy are associated with good relationship quality and spousal communication, which may reduce the likelihood that a husband has extramarital sex. Allendorf and colleagues observed that in Central India, a wife's autonomy was associated with her having fewer disagreements with her husband and with her husband prioritizing her over his parents. ${ }^{39}$ Another possible explanation for our findings is that women with higher levels of autonomy tend to marry men who do not engage in extramarital sex, though it is worth noting that the majority of marriages in India, especially in the North, are arranged by families. ${ }^{40}$

Our findings are consistent with the growing body of literature in India and elsewhere showing that among men, inequitable gender attitudes are associated with risky sexual behavior. ${ }^{8,11,24,41}$ A national study in India found that married and unmarried men who reported having had contact with a commercial sex worker in the past year were more likely than other men to express attitudes supporting sexual entitlement and wife abuse. ${ }^{8}$ A study of young Indian men showed that inequitable gender norms were associated with having had multiple sex partners, having symptoms of poor sexual health, having been physically or sexually violent with one's partner and using condoms less frequently. ${ }^{11}$ Research in China found that male adolescents with permissive attitudes regarding premarital sex had an elevated likelihood of holding inequitable genderrole attitudes. ${ }^{42}$ A potential explanation for our study findings is that cultural values surrounding masculinity may encourage risky sexual practices before and during marriage. ${ }^{26}$ In a qualitative study in India, young men described a "real man" (or asli mard) as being dominant and aggressive, and characterized women as chhav, an object or item to be possessed. Study participants indicated that verbal aggression, forced kissing and forced sex with women were acceptable, and that condom use was unnecessary even if they had multiple sex partners. ${ }^{43}$

Contrary to our expectations, we did not find a negative correlation (or any correlation) between a wife's autonomy and her husband's having inequitable gender attitudes. This lack of an association warrants further study, but it may be due to measurement issues or to conceptual differences between these measures. For example, the autonomy measure was asked of wives and encompassed a broad range of items, while the inequitable gender attitudes measure relied on the husband's responses and consisted of a few items that were relatively narrow in scope. Alternatively, the lack of correlation between these measures may be attributable to conflicting perceptions of gender relations between husbands and wives; a study among couples in Uttar Pradesh found that spouses' responses to the same autonomy items were only weakly associated, and that husbands' perceptions of their wives' autonomy were more strongly related to their wives' contraceptive use than were the wives' perception of their own autonomy. ${ }^{44}$

The finding that a wife's education and a couple's stan- 
dard of living were positively associated with the wife's autonomy is consistent with previous research. ${ }^{36}$ However, a husband's education and a couple's standard of living were not associated with a husband's inequitable gender attitudes, a finding that may reflect the ubiquity of these beliefs across socioeconomic classes in North India.

This study had several limitations. Because the data were collected in 2003, they may not capture current gender dynamics and HIV risks among couples in North India. However, to our knowledge, no study of this magnitude focusing on gender and HIV has been conducted in North India to date; many population-based studies, for example, have lacked detailed items on autonomy and gender attitudes. Moreover, trends in gender disparities and HIV prevalence suggest that our findings remain relevant and informative. In India, selective abortion of female fetuses increased markedly from 1980 to 2011, and among women aged 15-49 the median age at first marriage rose by less than a year from 1992 to $2006 .{ }^{45,46} \mathrm{Na}$ tional estimates showed that HIV prevalence stabilized or decreased in India's southern states from 2002 to 2007, but increased in some northern states. ${ }^{20,47}$

Other limitations of the study include its cross-sectional design, which precluded assessment of the direction of the associations we observed. Information on sexual behavior and STI symptoms was self-reported and thus susceptible to social desirability bias and misspecification errors. For instance, husbands may have underreported undesirable sexual behaviors and sexual health symptoms, and selfreported STI symptoms may have been nonspecific and due to causes other than STIs. Finally, the scale of inequitable gender attitudes may not be generalizable to other settings, since it was validated for our study population only.

Study strengths include the focused study design, our use of data that linked a husband's responses to his wife's, and the novel methodologies employed. Unlike other population-based surveys conducted in India, our survey collected data for the explicit purpose of investigating gender and HIV risks. In addition, members of the study team were from Uttar Pradesh, had experience with HIV risk factors in the region or both. These aspects of the study design potentially enhanced the quality of our data. Previous reports suggest that regional, focused studies elicit higher disclosure rates, particularly of sensitive information, than do large-scale, broad surveys. ${ }^{48,49}$ The study methods were unique because we examined both positive manifestations of gender-based power (autonomy) and negative manifestations of such power (inequitable gender attitudes) with respect to HIV risk, and structural equation modeling enabled us to estimate these associations simultaneously. For example, associations between a wife's autonomy and the couple's HIV risk were adjusted for associations between the husband's inequitable gender attitudes and HIV risk, and vice versa. Moreover, by using structural equation modeling, we were able to take into account correlated responses and error terms between spouses.

If our results reflect causal relationships between gender-based power and HIV risk, they suggest that HIV prevention programs in North India should address gender inequity as well as high risk behaviors in the general population. Thus far, gender transformative HIV interventions, which focus on modifying gender roles in order to promote more gender-equitable relationships, have demonstrated promise at the individual level, resulting in reduction of HIV risk, but community-level interventions have yielded mixed results. ${ }^{29,50-52}$ Our findings suggest ways to expand current research on gender-based power and HIV risk that may inform international and regional agencies' work at the community level. First, we found that examining multiple measures of gender-based power in a single study is worthwhile. This approach has the potential not only to capture a rich picture of the gender context in a study setting, but also to help identify gender dynamics that may conflict with HIV risk-reduction programs. Previous studies have shown that equitable and inequitable gender attitudes may coexist. ${ }^{53}$ A study in the Philippines found a U-shaped association between intimate partner violence and couples' decision making: Domination of decision making by either the husband or the wife was associated with elevated levels of marital violence, while joint decision making was associated with the lowest levels of marital violence. ${ }^{54}$ In South India, an evaluation of Stepping Stones, a training program that focuses on HIV awareness and promotion of relationship skills, found that residents of villages where the program was implemented expressed higher levels of equitable gender attitudes than did residents of other villages, but that regressive gender attitudes persisted one to three years after the intervention. Compared with the general population, residents of Stepping Stones villages were less likely to believe that "women should be blamed for spreading AIDS," but equally likely to agree that "raped women are usually at fault." 52 Therefore, future research should consider examining multiple measures of gender-based power and the interplay between these measures with respect to HIV risks. Measures related to sexual norms, cultural values and autonomy may be particularly informative. ${ }^{22,28,38,55}$

Second, studies that use community-level data, longitudinal designs and couple models to examine gender-based power and HIV risk are needed. Our findings, and those from emergent research, suggest the value of these approaches. A multilevel analysis of data from eight African countries showed that husbands residing in communities that supported wife-beating were more likely than other husbands to report engaging in risky extramarital sex. ${ }^{41} \mathrm{~A}$ study in four Indian states demonstrated that increases in women's autonomy (specifically freedom of movement) between 1998-1999 and 2002-2003 were associated with a reduced risk of marital violence initiation. ${ }^{38}$ Our study found that couples' gender dynamics were associated with HIV risk, and suggests that gender issues are important to consider in contexts where HIV spread is driven by husbands' high-risk, extramarital sexual behaviors. Although a meta-analysis of 29 couple-based HIV interven- 
tions revealed that the interventions increased condom use and reduced partner concurrency, few of the studies had explicitly addressed gender-based power at the couple level. ${ }^{56}$ Most HIV-related interventions that address gender issues are conducted either only with men or only with women. ${ }^{29}$

In conclusion, our findings add to the evidence linking gender-based power and HIV risk, though more research is needed to understand this association and to improve the efficacy of interventions that address gender issues at the community level. Future research in this area should assess the potential benefits of using multiple measures of gender inequity and employ innovative study designs. These approaches may inform the international agenda to make gender issues a standard component of HIV programs and facilitate community level change in India and other countries.

\section{REFERENCES}

1. Wingood GM and DiClemente RJ, Application of the theory of gender and power to examine HIV-related exposures, risk factors, and effective interventions for women, Health Education \& Behavior, 2000, 27(5):539-565.

2. World Health Organization (WHO), Strategy for Integrating Gender Analysis and Actions into the Work of WHO, Geneva: WHO, 2009.

3. President's Emergency Plan for AIDS Relief (PEPFAR), PEPFAR: Addressing Gender and HIV/AIDS, Washington, DC: PEPFAR, 2011.

4. Joint United Nations Programme on HIV/AIDS (UNAIDS), Operational Plan for UNAIDS Action Framework: Addressing Women, Girls, Gender Equality and HIV, Geneva: UNAIDS, 2010

5. Cohen J, HIV/AIDS: India slashes estimate of HIV-infected people, Science, 2007, 317(5835):179-181.

6. Kumar GA et al., Behavioral surveillance of premarital sex among never married young adults in a high HIV prevalence district in India, AIDS and Behavior, 2011, 15(1):228-235.

7. Singh RK and Joshi HS, Sexual behavior among truck drivers, Indian Journal of Public Health, 2012, 56(1):53-56.

8. Decker MR et al., Indian men's use of commercial sex workers: prevalence, condom use, and related gender attitudes, Journal of Acquired Immune Deficiency Syndromes, 2010, 53(2):240-246.

9. Vickerman P et al., To what extent is the HIV epidemic in southern India driven by commercial sex? A modelling analysis, AIDS, 2010, 24(16):2563-2572.

10. Arora P et al., HIV, HSV-2 and syphilis among married couples in India: patterns of discordance and concordance, Sexually Transmitted Infections, 2011, 87(6):516-520.

11. Verma R et al., Promoting Gender Equity as a Strategy to Reduce HIV Risk and Gender-Based Violence Among Young Men in India, Washington, DC: Population Council, 2008.

12. Sarna A et al., High uptake of HIV testing in a cohort of male injection drug users in Delhi, India: prevalence and correlates of HIV infection, AIDS and Behavior, 2013, 17(7):2479-2489.

13. Tsai AC and Subramanian SV, Proximate context of genderunequal norms and women's HIV risk in sub-Saharan Africa, AIDS, 2012, 26(3):381-386.

14. Pulerwitz J et al., Addressing gender dynamics and engaging men in HIV programs: lessons learned from Horizons research, Public Health Reports, 2010, 125(2):282-292.

15. Sgaier SK et al., Knowing your HIV/AIDS epidemic and tailoring an effective response: How did India do it? Sexually Transmitted Infections, 2012, 88(4):240-249.

16. Registrar General and Census Commissioner, Census of India
2011: Primary Census Abstract, Chapter 1, New Delhi: Registrar General and Census Commissioner, 2013, <http://www.censusindia.gov.in/201lcensus/PCA/PCA_Highlights/pca_highlights_file/ India/Chapter-1.pdf>, accessed Nov. 6, 2014.

17. Gates MF, TEDxChange: the big picture, 2012, <http://www. gatesfoundation.org/speeches-commentary/Pages/melinda-gates-tedxchange-big-picture-2012.aspx>, accessed Aug. 10, 2012.

18. International Institute for Population Sciences (IIPS) and Macro International, National Family Health Survey (NFHS-3), 2005-06, India: Volume 1, Mumbai: IIPS, 2007.

19. Saggurti N et al., Migration and HIV in India: Study of Select Districts, New Delhi: United Nations Development Programme, National AIDS Control Organisation (NACO) and Population Council, 2011.

20. NACO, HIV declining in India, news release, New Delhi: NACO, Dec. 1, 2010.

21. DePadilla L et al., Condom use among young women: modeling the theory of gender and power, Health Psychology, 2011, 30(3):310-319.

22. Pulerwitz J, Gortmaker SL and DeJong W, Measuring sexual relationship power in HIV/STD research, Sex Roles, 2000, 42(7-8):637660 .

23. Kershaw TS et al., The influence of power on HIV risk among pregnant women in rural Haiti, AIDS and Behavior, 2006, 10(3):309-318.

24. Shannon K et al., Gender inequity norms are associated with increased male-perpetrated rape and sexual risks for HIV infection in Botswana and Swaziland, PLoS ONE, 2012, 7(1):e28739, doi: 10.1371/ journal.pone.0028739, accessed Feb. 10, 2014.

25. Newmann $S$ et al., Marriage, monogamy and HIV: a profile of HIVinfected women in south India, International Journal of STD \& AIDS, 2000, 11(4):250-253.

26. Jewkes R and Morrell R, Gender and sexuality: emerging perspectives from the heterosexual epidemic in South Africa and implications for HIV risk and prevention, Journal of the International AIDS Society, 2010, Vol. 13, Art. 6, <http://www.biomedcentral.com/content/pdf/ 1758-2652-13-6.pdf>, accessed Feb. 10, 2014

27. Bloom SS, Wypij D and Das Gupta M, Dimensions of women's autonomy and the influence on maternal health care utilization in a north Indian city, Demography, 2001, 38(1):67-78.

28. Bloom SS and Griffiths PL, Female autonomy as a contributing factor to women's HIV-related knowledge and behaviour in three culturally contrasting states in India, Journal of Biosocial Science, 2007, 39(4):557-573.

29. Dworkin SL, Treves-Kagan S and Lippman SA, Gendertransformative interventions to reduce HIV risks and violence with heterosexually-active men: a review of the global evidence, AIDS and Behavior, 2013, 17(9):2845-2863.

30. Bloom SS, Singh S and Singh KK, What's acceptable to ask? Exploring questions about sexual behavior with women in North India, paper presented at the annual meeting of the Population Association of America, Minneapolis, MN, USA, May 1-3, 2003.

31. Balk D, Individual and community aspects of women's status and fertility in rural Bangladesh, Population Studies, 1994, 48(1):21-45.

32. de Vries D et al., Masculinity and the risk of HIV/AIDS in North India, paper presented at the 25th International Population Conference of the International Union for the Scientific Study of Population, Tours, France, July 18-23, 2005.

33. Bollen K, Structural Equations with Latent Variables, New York: John Wiley \& Sons, 1989.

34. Bollen K and Pearl J, Eight myths about causality and structural equation models, in: Morgan SL, ed., Handbook of Causal Analysis for Social Research, New York: Springer, 2013, pp. 301-328.

35. Hu L and Bentler PM, Cutoff criteria for fit indexes in covariance structure analysis: conventional criteria versus new alternatives, Structural Equation Modeling, 1999, 6(1):1-55.

36. Jejeebhoy SJ, Women's Education, Autonomy, and Reproductive Behaviour: Experience from Developing Countries, Oxford, UK: Clarendon Press, 1995. 
37. Sudha S and Morrison S, Marital violence and women's reproductive health care in Uttar Pradesh, India, Women's Health Issues, 2011, 21(3):214-221.

38. Bourey C, Stephenson R and Hindin MJ, Reproduction, functional autonomy and changing experiences of intimate partner violence within marriage in rural India, International Perspectives on Sexual and Reproductive Health, 2013, 39(4):215-226.

39. Allendorf K, Women's agency and the quality of family relationships in India, Population Research and Policy Review, 2012, 31(2):187-206.

40. Desai $S$ and Andrist L, Gender scripts and age at marriage in India, Demography, 2010, 47(3):667-687.

41. Stephenson R, Community-level gender equity and extramarital sexual risk-taking among married men in eight African countries, International Perspectives on Sexual and Reproductive Health, 2010, 36(4):178-188

42. Zuo X et al., Gender differences in adolescent premarital sexual permissiveness in three Asian cities: effects of gender-role attitudes, Journal of Adolescent Health, 2012, 50(3 Suppl.):S18-S25.

43. Verma RK et al., Challenging and changing gender attitudes among young men in Mumbai, India, Reproductive Health Matters, 2006, 14(28):135-143.

44. Jejeebhoy SJ, Convergence and divergence in spouses' perspectives on women's autonomy in rural India, Studies in Family Planning, 2002, 33(4):299-308.

45. Jha P et al., Trends in selective abortions of girls in India: analysis of nationally representative birth histories from 1990 to 2005 and census data from 1991 to 2011, Lancet, 2011, 377(9781):1921-1928.

46. Kishor S and Gupta K, Gender Equality and Women's Empowerment in India, Mumbai: IIPS; and Calverton, MD, USA: ICF Macro, 2009.

47. John TJ et al., Continuing challenge of infectious diseases in India, Lancet, 2011, 377(9761):252-269.

48. Ellsberg $\mathrm{M}$ et al., Researching domestic violence against women methodological and ethical considerations, Studies in Family Planning, 2001, 32(1):1-16.

49. Rajan SI and James K, Third National Family Health Survey in India: issues, problems and prospects, Economic \& Political Weekly, 2008, 43(48):33-38

50. Das A et al., Reviewing responsibilities and renewing relationships: an intervention with men on violence against women in India, Culture, Health \& Sexuality, 2012, 14(6):659-675.

51. Raj A et al., Randomized controlled trial to test the RHANI Wives HIV intervention for women in India at risk for HIV from husbands, AIDS and Behavior, 2013, 17(9):3066-3080.

52. Bradley JE et al., Evaluation of Stepping Stones as a tool for changing knowledge, attitudes and behaviours associated with gender, relationships and HIV risk in Karnataka, India, BMC Public Health, 2011, Vol. 11, Art. 496, doi: 10.1186/1471-2458-11-496, accessed Feb. 10, 2014

53. Jewkes RK et al., Intimate partner violence, relationship power inequity, and incidence of HIV infection in young women in South Africa: a cohort study, Lancet, 2010, 376(9734):41-48.

54. Hindin MJ and Adair LS, Who's at risk? Factors associated with intimate partner violence in the Philippines, Social Science \& Medicine, 2002, 55(8):1385-1399.

55. Kostick KM et al., A methodology for building culture and gender norms into intervention: an example from Mumbai, India, Social Science \& Medicine, 2011, 72(10):1630-1638.

56. LaCroix JM et al., Behavioural interventions to reduce sexual risk for HIV in heterosexual couples: a meta-analysis, Sexually Transmitted Infections, 2013, 89(8):620-627.

\section{RESUMEN}

Contexto: La desigualdad de género es un impulsor largamente reconocido de la epidemia del VIH. Sin embargo, pocos estudios han investigado la asociación entre el poder basado en el género y el riesgo de contraer el VIH en la India, país que tiene la tercera epidemia del VIH más grande del mundo.

Métodos: Se utilizaron datos de población recolectados en 2003 sobre 3385 parejas que residian en Uttar Pradesh y Uttarakhand, en el norte de la India, para examinar las asociaciones entre el poder basado en el género (autonomía de la esposa y actitudes de género inequitativas del esposo) y los indicadores del riesgo de contraer el VIH de las parejas (si el esposo había tenido relaciones sexuales premaritales con una persona distinta a su actual esposa, relaciones sexuales extramaritales en el pasado año o síntomas de ITS en el pasado año). Se utilizó la técnica de modelación de ecuaciones estructurales para crear variables compuestas de las medidas del poder basado en el género y para probar sus asociaciones con las medidas del riesgo de contraer el VIH.

Resultados: Veinticuatro por ciento de los esposos había tenido relaciones sexuales premaritales, $7 \%$ había tenido relaciones extramaritales en el pasado año y 6\% había tenido sintomas de ITS en el pasado año. Los modelos de ecuaciones estructurales indicaron que las esposas que reportaron altos niveles de autonomía tuvieron una menor probabilidad que otras de tener esposos que habían tenido relaciones sexuales extramaritales en el pasado año (asociación directa) y síntomas de ITS en el pasado año (asociación indirecta). Además, los esposos que apoyaron normas de género más inequitativas tuvieron una mayor probabilidad que otros de reportar haber tenido relaciones sexuales premaritales lo que, a su vez, se asoció con haber tenido relaciones sexuales extramaritales $y$ sintomas de ITS en el pasado año.

Conclusiones: Si las asociaciones identificadas en este estudio reflejan una relación causal entre el poder basado en el género y el comportamiento de riesgo de contraer el VIH, entonces los programas de prevención del VIH que han abordado exitosamente los roles de género inequitativos pueden reducir los riesgos de contraer el VIH en el norte de la India.

\section{RÉSUMÉ}

Contexte: L'inégalité des sexes est depuis longtemps reconnue comme alimentant l'épidémie du VIH. Peu d'études ont cependant examiné l'association entre le pouvoir sexiste et le risque de contraction du VIH en Inde, en troisième position sur la liste mondiale d'importance de l'épidémie du VIH.

Méthodes: Les données de population collectées en 2003 auprès de 3385 couples résidant dans les états d'Uttar Pradesh et de Uttarakhand, dans le nord de l'Inde, ont servi à examiner les associations entre le pouvoir sexiste (autonomie de la femme et attitudes sexistes du mari) et les indicateurs de risque de contraction du VIH des couples (si le mari avait eu des rapports sexuels antérieurs au mariage avec une personne autre que sa femme actuelle, une sexualité extraconjugale durant les 12 derniers mois ou des symptômes d'IST durant les 12 derniers mois). La modélisation par équations structurelles a permis la création de variables composées des mesures de pouvoir sexiste et le test de leurs associations avec les mesures de risque de contraction du VIH.

Résultats: Vingt-quatre pour cent des maris avaient eu des rapports sexuels antérieurs au mariage; 7\%, une activité 
sexuelle extraconjugale pendant les 12 derniers mois et 6\%, des symptômes d'IST durant les 12 derniers mois. Les modèles d'équations structurelles indiquent que les femmes faisant état de niveaux d'autonomie supérieurs sont moins susceptibles que les autres d'avoir un mari ayant eu une activité extraconjugale (association directe) ou des symptômes d'IST (association indirecte) durant les 12 derniers mois. De plus, les maris favorables à des normes de genre moins égalitaires se sont révélés plus susceptibles que les autres d'avoir fait état de rapports sexuels antérieurs au mariage, à leur tour associés à la sexualité extraconjugale et aux symptômes d'IST durant les 12 derniers mois.

Conclusions: Si les associations identifiées dans cette étude reflètent un rapport causal entre le pouvoir sexiste et le comportement à risque VIH, les programmes de prévention du VIH qui abordent avec succès la question des rôles sexuels inégaux pourraient réduire les risques de contraction du VIH dans le nord de l'Inde.

\section{Acknowledgments}

The authors acknowledge support from the National Institute for Child Health and Human Development (grant NIH-NICHD T32HD07168 to the Carolina Population Center) and the National Institute of Mental Health (grant NIH-NIMH T32MH020031). They thank Kaushalendra K. Singh and staff at Banaras Hindu University, Varanasi, Uttar Pradesh, who headed the data collection team in Uttar Pradesh. The content of this article is the responsibility solely of the authors and does not necessarily represent the official views of the National Institutes of Health.

Author contact: alpna.a.agrawal@uth.tmc.edu 